MS19-P05

\section{Local structure of the supported Keggin and Wells-Dawson heteropolyacids and its consequence on their (photo)catalytic activity}

Giuseppe Marci ${ }^{1}$, Elisa García-López ${ }^{1}$, Leonardo Palmisanoํㅡㄹ Igor

Krivtsov $^{2}$, Aida Serrano ${ }^{3}$

1. Department of Energy, Information Engineering and Mathematical Models (DEIM), University of Palermo, Palermo, Italy

2. Chemical and Environmental Engineering, University of Oviedo, Oviedo, Spain

3. Spanish CRG BM25 SpLine Beamline at the ESRF, Grenoble, France

email: giuseppe.marci@unipa.it

Keggin and Wells-Dawson heteropolyanions, $\mathrm{PW}_{12} \mathrm{O}_{40}{ }^{3-}$ and $\mathrm{P}_{2} \mathrm{~W}_{18} \mathrm{O}_{62}{ }^{6-}$, respectively, are nanosized transition metal-oxygen clusters belonging to the heteropolyacids (HPAs) family. They are widely used as catalysts, due to their strong Brönsted acidity, and their dispersion on solid supports favours the accessibility to their acid sites increasing their catalytic activity. Notably, the UV-irradiation significantly increases their catalytic performance [1].

A series of binary materials composed of Keggin or Wells-Dawson HPAs and $\mathrm{SiO}_{2}, \mathrm{TiO}_{2}, \mathrm{ZrO}_{2}$ or $\mathrm{C}_{3} \mathrm{~N}_{4}$ has been prepared by impregnation and/or solvothermal methods. Remarkable differences in the (photo)catalytic activities of unsupported HPAs and binary materials are related to the structural changes of the supported HPAs due to the cluster-support interaction, which modifies their acidic strength and redox potentials. The nature of the support, particularly its acidic or basic character, defines the state of the deposited HPA. The application of XAS allowed to study the modes of interaction between the metal-oxide cluster and the support surface. Fitting of W L3-edge EXAFS spectrum of the HPA/ $/ \mathrm{SiO}_{2}$ prepared by impregnation revealed only a slight increment of the coordination number of the tungsten atom both in $\mathrm{W}=\mathrm{O}$ and $\mathrm{W}-\mathrm{O}-\mathrm{W}$ bonds, suggesting that the supported HPA remained almost intact. The solvothermal impregnation, although gave almost the same result for silica support, drastically affected the W arrangement in HPA/ $\mathrm{TiO}_{2}$ and $\mathrm{HPA} / \mathrm{ZrO}_{2}$. The increase of the coordination number of $\mathrm{W}=\mathrm{O}$ and the decrease of that of the $\mathrm{W}-\mathrm{O}-\mathrm{W}$ implies the occurrence of strong HPA interactions with the $\mathrm{TiO}_{2}$ and $\mathrm{ZrO}_{2}$ surfaces. For the solvothermal preparation of the HPA-oxide composites the increase of the $\mathrm{W}=\mathrm{O}$ coordination number followed the sequence $\mathrm{SiO}_{2}<\mathrm{TiO}_{2}<\mathrm{ZrO}_{2}$ having the values of $1.25,3.80,4.40$, respectively. This dramatic change could be explained by the partial destruction of the HPA cluster forming $\mathrm{WO}_{3}$ species. These changes, in addition to the bulk and surface features of the supported HPAs, influenced the reaction performance of the (photo)catalytic propylene hydration [3] and 2-propanol dehydration [4,5] to a significant extent.
References:

[1] G. Marcì, E. I. García-López, L. Palmisano, Eur. J. Inorg. Chem. (2014) 21-35.

[2] G. Marcì, E. García-López, M. Bellardita, F. Parisi, C. ColbeauJustin, S. Sorgues, L. F. Liotta, L. Palmisano, Phys. Chem. Chem. Phys. 15 (2013) 13329-13342.

[3] E. I. García-López, G. Marcì, F. R. Pomilla, A. Kirpsza, A. Micek-Ilnicka, L. Palmisano, Appl. Catal. B 189 (2016) 252-265. [4] E. I. García-López, G. Marcì, F. R. Pomilla, L. Palmisano, Appl. Catal. A 528 (2016) 113-122.

Keywords: heteropolyacid, polyoxometalate, Keggin, WellsDawson, structure-reactivity influence, catalysis, photocatalysis, XAS, XANES, EXAFS 